\title{
ODONTOLOGIA DO ESPORTE - UMA PROPOSTA INOVADORA
}

SPORTS DENTISTRY - AN INNOVATIVE PROPOSAL

ODONTOLOGÍA DEL DEPORTE - UNA PROPUESTA INNOVADORA

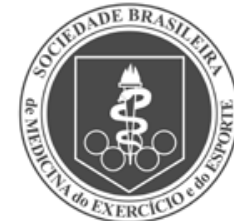

Artigo de ReVisão

REVIEW ARTICLE

ARtículo de REVISIÓN
Giuseppe Umberto Pastore ${ }^{1}$

(Cirurgião Dentista)

Márcia Moreira' (Cirurgiã Dentista)

Robson Bastos' (Cirurgião Dentista)

Marcelo Galotti ${ }^{1}$ (Cirurgião Dentista)

Mario Francisco de Pasquali Leonardi ${ }^{1}$ (Cirurgião Dentista)

1. SBOEE - Sociedade Brasileira de Odontologia do Exercício e do Esporte, São Paulo, SP, Brasil.

\section{Correspondência:}

Avenida Brigadeiro Faria Lima, 1616, Conj., 701, Jardim Paulistano, São Paulo, SP, Brasil. 01451-001. giuseppe.u.pastore@gmail.com

\section{RESUMO}

O objetivo deste trabalho é inserir definitivamente a odontologia no contexto do esporte de alto rendimento, com o firme propósito de estabelecer uma linguagem comum com a medicina do esporte. Consideramos que as práticas clínicas aplicadas a atletas de alto desempenho devem obedecer a regras e momentos adequados, levando-se em conta o contexto das demandas relativas aos atletas de ponta, ou seja, o desgaste fisiológico e o processo adaptativo ao sobre-esforço, e todas as suas consequências. A odontologia dentro dos clubes esportivos promoveria a saúde bucal e sistêmica dos atletas, controlando lesões bucais em integração com outros departamentos da área médica, equilíbrio hídrico, controle dietético, sobretreinamento e uso de energéticos e isotônicos. Quando as ações educativas forem inseridas desde a infância nas práticas esportivas, teremos, certamente, menor número de problemas bucais com mais necessidades preventivas que curativas. Sugerimos para as categorias de base, para atletas em formação, a inclusão de um odontopediatra nos clubes esportivos, como um profissional de importante atuação em saúde.

Descritores: odontologia; esportes; infecção focal; saúde bucal; atletas; periodontia.

\section{ABSTRACT}

The purpose of this work is to definitively insert Dentistry in the context of high performance sports, with the main goal of establishing a common language with Sports Medicine. We consider that the clinical practices applied to high performance athletes should obey appropriate rules and moments, taking into account the context of the demands on the top athletes, i.e., the physiological wastage and the adaptive process to over-effort, and all its consequences. Dentistry inside the sports clubs would promote the oral and systemic health of athletes, controlling oral lesions integrated with other medical departments, water balance, dietary control, overtraining, and the intake of energy and isotonic drinks. When educational actions are inserted since childhood in sports practices, we will certainly havefewer oral problems with more preventive than curative needs. We suggest for the basic categories, for athletes in training, the inclusion of a pediatric dentist in sports clubs, as a health professional who plays an important role.

Keywords: dentistry; sports; focal infection; oral health; athletes; periodontics.

\section{RESUMEN}

El objetivo de este trabajo es, sin duda introducir la odontología en el contexto del deporte de alto rendimiento, con el firme propósito de establecer un lenguaje común con la medicina deportiva. Creemos que la práctica clínica aplicada a los atletas de alto rendimiento deben obedecer las reglas y los momentos apropiados, teniendo en cuenta el contexto de las demandas relacionadas con atletas de alto rendimiento, es decir, el desgaste fisiológico y el proceso de adaptación a un exceso de ejercicio, y todas sus consecuencias. La odontología, en los clubes deportivos promovería la salud oral y sistémica de los atletas mediante el control de las lesiones orales, interactuando con otros departamentos médicos, el balance hídrico, control de la dieta, el sobreentrenamiento y el consumo de bebidas energéticas e isotónicas. Cuando se introducen actividades educacionales desde la infancia en las prácticas deportivas, sin duda vamos a tener problemas dentales menores, con mayor necesidad de prevención en lugar de curación. Sugerimos a las categorías básicas, para los atletas en formación, incluir un dentista pediátrico en los clubes deportivos, como profesional de importante acción relacionada con la salud.

Descriptores: odontología; deportes; infección focal; salud bucal; atletas; periodoncia.

\section{INTRODUÇÃO}

O objetivo deste trabalho é o de inserir definitivamente a odontologia no contexto da prática do esporte de alto rendimento; não só como recurso de saúde individual, mas, sobretudo, como ferramenta de prevenção em relação a lesões musculares, articulares e de ligamentos, enfim a medicina da cavidade bucal do atleta, para as equipes de base e profissionais de qualquer clube, associação, federação e confederações esportivas. Também na indicação de prevenção e promoção de saúde bucal, na prática de qualquer atividade esportiva e exercício físico para a população em geral, como parte da educação em saúde.

Segundo Hernandez' a Medicina Esportiva é uma especialidade médica que apresenta uma forte evidência multidisciplinar, que envolve o atendimento em todas as faixas etárias; da criança ao idoso, tanto da população em geral, quanto de atletas de alto rendimento 
em jogos competitivos entre clubes, maratonas ou aventura; e até mesmo nas Olimpíadas.

Da mesma forma, todas as outras profissões de saúde que atuam atreladas ao departamento médico de uma entidade esportiva, têm esse objetivo, isto é, buscam priorizar o rendimento do atleta ou da equipe esportiva.

Assim, a partir de uma situação de homeostase, o fisiologista do esporte, aplicando os conceitos da fisiologia do exercício ao desempenho esportivo, dispõe de recursos que podem aumentar a performance de determinado atleta. Profissionais de saúde que atuam nesse segmento, o psicólogo, o nutricionista, o fisioterapeuta usando seus recursos e conhecimentos também o fazem. É imprescindível a inserção da odontologia, na prática da saúde esportiva, no cumprimento da promoção da saúde e na promoção do alto desempenho esportivo.

A Literatura mostra que o excesso de treinamento ("overtraining"), a necessidade de equilíbrio hídrico, a natureza da dieta, o uso contínuo de isotônicos e energéticos, o risco de imunossupressão, a pressão comportamental e emocional pelo excelente desempenho esportivo, entre outros, são características da vida do atleta que têm consequências importantes na cavidade bucal. O controle e trânsito de micro-organismos da boca para outros nichos do corpo físico, tanto a nível sistêmico, (humoral e celular) como local, (quantidade de fluxo e composição da saliva), podem estar significativamente alterados em atletas submetidos a altas cargas de treinamento.

Consideramos, também, que o pleno conhecimento da etiologia e patogenia da doença periodontal e das patologias pulpares com seus desdobramentos, e os princípios da medicina periodontal, sejam alguns pré-requisitos para o bom entendimento do processo de acompanhamento e controle de saúde bucal para atletas de alto rendimento. Justificando, assim, a incorporação dos cirurgiões-dentistas nas equipes de profissionais de saúde que acompanham qualquer equipe esportiva, sobretudo, nas categorias profissionais.

\section{Revisão de literatura}

Os traumas dentários nas práticas esportivas são os pontos principais de intersecção entre os esportes e a odontologia; e segundo Andreasen², a combinação entre a violência, acidentes de trânsito e as atividades esportivas estabeleceram os traumas dentários como um problema de saúde pública nos E.U.A.

As condições da cavidade bucal de 400 atletas de futebol, do time da Portuguesa, foram avaliadas por Rosa et al. ${ }^{3}$ que encontraram um grande número de dentes com cavidades e lesões bucais em tecidos moles, na grande maioria dos jogadores. Entre os jogadores do time de Base, $71 \%$ apresentaram lesões de cárie e $14 \%$ focos infecciosos dentais. Dos jogadores do time profissional 68\% apresentaram lesões de cárie e 23 \% focos infecciosos dentais; destacando a importância da odontologia nos cuidados de saúde das equipes de profissionais do esporte no controle de focos de infecção.

A imunossupressão, tanto a nível sistêmico quanto a nível local, é uma das características da prática do esporte de alto rendimento. Martinez e Avarez-Moon ${ }^{4}$, afirmam que a atividade física está associada a variações do comportamento fisiológico, psicológico e do sistema neuroendócrino. O estresse causado pelo intenso exercício físico, promove descargas de catecolaminas, (adrenalina e noradrenalina), que influenciam a maioria dos processos fisiológicos. Em consequência da inflamação gerada pelo exercício, as alterações imunológicas desencadeiam alterações sistêmicas, como aumento de temperatura, astenia, pré-disposições a infecções, com redução do desempenho esportivo. Sobretudo as alterações cárdio-vasculares e neuro-endócrinas, geradas pela intensidade do exercício, são as principais causas de distúrbios do sistema imunológico.
Qualquer doença infecciosa, por mais clinicamente leve que seja, pode causar diminuição do desempenho do atleta.

Estudando as respostas hormonais e metabólicas ao exercício em crianças e adolescentes, Boisseau e Delamarche ${ }^{5}$, concluíram que existe pouca literatura sobre o tema, mas há estudos mostrando que há variações por faixa etária, ligadas à prática de exercício do moderado ao intenso. Estas respostas em crianças e adolescentes também são diferentes das do adulto, sendo que na criança há uma imaturidade da resposta glicolítica na pré-puberdade. As crianças são mais bem adaptadas aos exercícios aeróbicos porque seu aproveitamento energético parece estar mais relacionado ao metabolismo oxidativo, do que nos adultos. A atividade glicolítica cresce com a idade e a relativa proporção de utilização de gordura durante o exercício prolongado parece maior nas crianças que nos adultos.

Realizando uma revista de Literatura, Feres e Figueiredo ${ }^{6}$, abordando o conceito de infecção focal, descreveram que a doença periodontal pode prover bactérias da cavidade oral para outras áreas do organismo ou caracterizar o estabelecimento de um quadro de uma doença sistêmica crônica. Concentrações plasmáticas elevadas de mediadores químicos oriundos da inflamação crônica sustentada pela doença periodontal na boca, pode interferir com a evolução de outras doenças sistêmicas, seu início e/ou sua progressão.

Melo da Silva et al. ${ }^{7}$, discutiu a doença periodontal e focos endodônticos como fator de risco para doenças sistêmicas. As bactérias de infecções orais podem utilizar duas vias para induzirem manifestações sistêmicas. A primeira seria quando a disseminação ocorre por uma bacteremia transitória, causada por procedimentos dentários em regiões infectadas. Esta bacteremia não excede mais de 1 hora e os microrganismos são rapidamente destruídos pelas defesas do hospedeiro, a não ser que o paciente apresente fatores predisponentes e desta forma, uma infecção focal pode se instalar. A segunda via seria pela disseminação de complexos imunes ou por meio de antígenos solúveis, que se combinam a anticorpos circulantes, podendo se depositar em outras regiões do organismo, induzindo reações de hipersensibilidade imunológica. Entretanto, os complexos imunes formados em lesões peri-radiculares crônicas ficam confinados, não sendo distribuídos sistemicamente. Por outro lado, em casos de abscesso agudo, os níveis circulantes de complexos imunes são superiores, podendo causar reações imunológicas sistêmicas. Aconselham os cirurgiões-dentistas, especialmente os endodontistas, devam estar atentos a medidas profiláticas na manipulação de problemas infecciosos de origem bucal, principalmente no tratamento de pacientes de risco para complicações sistêmicas. Para os pacientes de risco, a British Society for Antimicrobial Chemotherapy, recomenda antibioticoterapia para qualquer manipulação dental periodontal ou endodôntica, para qualquer paciente. A American Heart Association, no entanto, só recomenda a cobertura com antibiótico para pacientes com risco cardíaco associado. As bactérias mais frequentes são anaeróbicas.

Estudando in vitro, a ação erosiva sobre o esmalte dentário, resultante da frequente ação de contato com bebidas energéticas, Matsumoto ${ }^{8}$ experimentou 10 bebidas energéticas mais comercializadas e encontrou potencial erosivo evidente em todas elas, devido ao baixo $\mathrm{pH}$. Portanto se pode inferir que atletas que ingerem líquidos energéticos em alta frequência podem sofrer erosão do esmalte superficial de seus dentes e isto pode ser prevenido com a orientação do cirurgião-dentista para a forma de consumo de energéticos. Uma bebida energética contém vários produtos, mas os principais, a cafeína e a taurina, aliviam o cansaço muscular. A cafeína era proibida pelo Comitê Olímpico até 2004, quando foi liberada.

Um Isotônico é uma bebida destinada a reidratar; bem como repor eletrólitos, carboidratos e outros nutrientes. Contém uma quantidade de 
sódio que varia entre 50 a 160 mg por garrafa; sendo por isto, contra-indicados para pessoas com hipertensão arterial, insuficiência cardíaca e doenças renais. Cavalcanti et al. ${ }^{9}$, avaliaram in vitro, o efeito erosivo de bebidas isotônicas sobre o esmalte dentário. Estudaram nove produtos comercializados, e seu potencial ácido sobre o esmalte, em temperatura ambiente ou resfriado $\left( \pm 9^{\circ} \mathrm{C}\right)$. Todas as bebidas possuem $\mathrm{pH}$ bem abaixo do considerado crítico para a desmineralização do esmalte dental $(5,5)$ e, portanto, têm a capacidade de produzir efeito erosivo sobre esta superfície. As bebidas isotônicas resfriadas, em geral, apresentaram um pH maior quando comparadas às mesmas em temperatura ambiente. Portanto, comprovou-se o potencial capacidade erosiva dos isotônicos sobre o esmalte dentário, principalmente quando consumidas em alta frequência e à temperatura ambiente. Deve-se ter em mente que in vivo, teremos a composição da saliva como potencial remineralizador; a capacidade tampão e o fluxo salivar atuando como fatores protetores da estrutura mineral do esmalte e dos tecidos dentais. Porém, nos atletas de alto rendimento que ingerem estes produtos várias vezes ao dia para reidratação e reposição da capacidade energética, os cuidados para evitar a erosão dentária devem ser maiores e praticados.

O ACSM, American College of Sports Medicine, indica que a hidratação do atleta e sua reidratação devem ser prévias e contínuas durante e após o exercício, principalmente se este durar mais de 1 hora, ou se estender por mais horas. Silva et al. ${ }^{10}$, recomendam que a hidratação deva ser lenta e ter início por volta de 4 horas antes do exercício. Indica-se ainda a ingestão de bebidas com teor de sódio embutidos e o consumo de alimentos com alto teor de sódio, pois estes estimulam a sede e retém a urina. Recomendam a ingestão de bebidas que contenham de 6 a $8 \%$ de glicídios para atividades esportivas superiores à 1 hora. O sódio ajuda a estimular a sede, enquanto que o potássio é importante para alcançar a reidratação, uma vez que leva à retenção de água no espaço intracelular. Uma associação internacional, A National Athletic Trainer's Association (NATA), recomenda a ingestão de 500 a $600 \mathrm{ml}$ de água ou outra bebida repositória de duas a três horas antes do início da atividade e faltando 10 a 20 minutos para o início que haja a ingestão de 200 a 300 ml.

A saliva tem sido apontada nas últimas décadas como um marcador da atividade adrenérgica, sobretudo no estresse e na atividade física, o que indica a necessidade de uma gama imensa de pesquisas neste campo. Além disto, a facilidade de coleta, o baixo custo e a facilidade de acesso ao volume de substância salivar produzida por indivíduo, destacam a saliva como indicador da função do sistema nervoso e da hidratação corporal sistêmica do atleta. Na pesquisa de Segura et al. ${ }^{11}$, verificaram correlação entre a concentração do lactato salivar e do lactato sanguíneo. Nas condições de exercício prolongado ocorrem limitações do metabolismo aeróbico e é necessário o aproveitamento da glicólise em condições anaeróbicas, causando um aumento do lactato sanguíneo, que aparece também na saliva, com forte correlação.

Cheuvront e Sawka ${ }^{12}$ relataram aumento da densidade salivar quando de intensa sudorese. Tais achados podem sugerir que as propriedades salivares podem estar comprometidas ou ainda parcialmente comprometidas em atletas de alto rendimento, desfavorecendo a integridade da mucosa, a manutenção da integridade mineral da estrutura do esmalte dentário e as defesas intrínsecas às estruturas periodontais frente às bactérias e seus produtos de metabolismo.

No estudo de Kivlighan e Grange ${ }^{13}$, a alfa amilase salivar foi avaliada individualmente por atleta, após esportes competitivos. Na média, a amilase salivar teve um aumento de $156 \%$ após atividade ergométrica e a maior concentração parece estar associada a um perfil de maior competitividade, com complexa integração comportamental e psicológica.

Realizando uma revisão sistemática da influência do exercício físico sobre o comportamento do sistema imunológico, Silva et al. ${ }^{14}$, estudaram especialmente a IgA-salivar, que é a imunoglobulina protetora do trato superior do aparelho respiratório. O controle dessa variável em atletas se torna extremamente relevante e viável, principalmente no controle de infecções do trato respiratório superior, pois sua concentração diminui sensivelmente quando em atividades físicas intensas, retornando à normalidade após 48 horas de repouso do atleta. Sugerem que a constante supervisão dos níveis de lgA-salivar poderia prevenir a ocorrência de infecções oportunistas em épocas de maior atividade esportiva e de maior intensidade de treinamentos. Discutem que a constante hidratação durante a ação esportiva com a reposição de carboidratos, a organização do calendário de treinos e a aclimatação do atleta, podem diminuir o risco de saúde sistêmica para o atleta de alto rendimento.

McArdle et al. ${ }^{15}$, em seus estudos relatam que toda água que compõe um organismo está distribuída basicamente em dois compartimentos: intracelular, líquido dentro da célula e extracelular (plasma), líquido intersticial, que banham órgãos e tecidos. A perda de líquidos corporais em decorrência da intensa sudorese em atletas submetidos regularmente a grandes esforços físicos, em muitas ocasiões não é reposto integralmente mesmo ingerindo-se o volume perdido e acrescido de eletrólitos. No atleta a ação da saliva está prejudicada tanto no que se refere à quantidade de fluxo, como na composição e picos de ação bacteriana, similares aos que ocorrem no período do sono, podem acontecer em consequência da intensa desidratação em função dos treinamentos. Além disto, a ocorrência de refluxos gástricos, com maior prevalência nos períodos de adaptação, em temporadas de competição, interferem na ação ácida sobre as estruturas dentais e a diminuição de volume hídrico.

Santos Oliveira et al. ${ }^{16}$, destacam o emprego da saliva na análise dos níveis de hidratação corporal total e do metabolismo anaeróbio e da máxima fase estável de lactato, referenciando Segura et al. ${ }^{11}$, e sugerem qualidade na metodologia da coleta da saliva como alternativa minimamente invasiva, em experimentos na área do exercício físico.

As condições de saúde bucal dos atletas que participaram dos Jogos Olímpicos de 2012, em Londres foram avaliadas por Needleman et al. ${ }^{17}$. Participaram da amostra 278 atletas da África, América e Europa, brancos e negros, com idade média de 25,7 anos, praticantes de 25 diferentes esportes. 46,5\% dos atletas descreveram que há pelo menos 12 meses não visitaram um dentista e que 8,7 \% nunca foram ao dentista. 55,1\% tinham Cárie com $41 \%$ das cavidades em dentina, 44,6\% apresentavam erosão semelhante em dentes anteriores e posteriores, sendo que a severidade era de grau 2-3. 30\% tinham história de traumas buco-faciais, sendo que 17,3\% apresentaram novos traumas na competição. 75\% dos atletas tinham gengivites em grau 1-2 e 15\% tinham periodontite em grau irreversível, nível 3-4. Os autores se surpreenderam com os altos índices de problemas bucais em atletas de elite, e destacaram que a grande maioria deles poderia ter sido evitada com a associação de cuidados odontológicos dentro da equipe médica. Sequer houve associação entre estes resultados e a localização continental dos atletas. Lamentaram que esta interação não estivesse ocorrendo mesmo para os atletas de elite em todos os continentes participantes dos Jogos Olímpicos em 2012 e que o mal estado da saúde bucal provoca um impacto negativo no bem-estar geral do atleta, seu treinamento e rendimento final.

Atualmente, considera-se o bruxismo um fenômeno induzido centralmente no sistema nervoso e não relacionado a fatores locais, segundo Fernandes ${ }^{18}$. Embora sendo de etiologia complexa, é muito comum em atletas, podendo causar desgastes nas superfícies dentárias e dores musculares, faciais e cefálicas dependendo da sua intensidade. Além disso, foi identificada correlação positiva entre o aumento da concentração de catecolaminas, uma condição presente em atletas, na urina e os estados de ansiedade e outras anormalidades emocionais do estresse. 
Alguns estudos epidemiológicos investigaram a associação entre condição dentária e capacidade física funcional em indivíduos idosos e mostraram que a diminuição da saúde dental e menor capacidade de mastigação estão relacionadas com menor performance física ${ }^{19,20}$.

A relação funcional entre os músculos da postura corporal e os do sistema estomatognático tem sido abordada em estudos relacionados à oclusão dentária. Durante apertamento dentário voluntário em indivíduos dentados, foi encontrado registros eletromiográficos de co-ativação dos músculos mastigatórios (m. masseter e m. temporal), posturais do pescoço ( $m$. esternocleidomastoideo e $m$. trapézio), tronco ( $m$. paravertebrais e $m$. reto abdominal) e membros inferiores ( $m$. soleus e m. gastrocnemius ventro medial e lateral), por Silva et al. ${ }^{21}$ Entretanto, não existem dados que mensurem a força muscular desenvolvida por estes músculos durante a prática esportiva, na qual é muito comum o apertamento dentário em oclusão.

A inserção do cirurgião-dentista nas equipes multidisciplinares de saúde que atendem atletas sejam em clubes, associações, confederações e mesmo no atendimento de pacientes que praticam esportes de confronto ou velocidade, foi destacada por Costa 22 , enfatizando a importância para que indique e utilize o uso de protetores bucais nestas modalidades. Convida a classe odontológica a se mobilizar pelo reconhecimento da especialidade de Odontologia do Esporte.

Estudando a inserção do fisioterapeuta nos clubes brasileiros, Silva et al. ${ }^{23}$, analisou também a composição da interdisciplinaridade dentro dos clubes, entrevistando 49 fisioterapeutas contratados. Concluiu que dos profissionais de saúde, o cirurgião-dentista foi citado como o mais esporadicamente contratado.

Descrevendo sobre os protetores bucais e sua indicação na prática esportiva, Tuna e Ozel ${ }^{24}$ relacionaram a existência de diversos tipos de protetores; os pré-fabricados e os sob medida (individualizados). As propriedades essenciais dos materiais utilizados na confecção dos protetores incluem a absorção de água, densidade e espessura, bem como a transmissão de temperatura, absorção de energia e resistência. A odontologia tem um papel importante na individualização do desenho do protetor bucal segundo as necessidades do atleta.

A principal função dos dispositivos intra-orais, segundo Yavich apud $\mathrm{Assis}^{25}$, é melhorar a relação de posição da cabeça da mandíbula em relação à fossa articular. Com isso, o dispositivo vai atuar como uma espécie de palmilha individualizada; fazendo com que as cadeias musculares funcionem em perfeita harmonia, abrindo mais as vias aéreas e proporcionando uma melhor oxigenação.

Moreira e Lino ${ }^{26}$ realizaram um estudo comparativo entre os arcos dentários de respiradores nasais e bucais, na fase de dentição decídua e obtiveram os seguintes resultados. A distância entre segundos molares decíduos não teve diferença significante, porém a distância entre caninos teve diferença significante em $0,1 \%$ e a profundidade palatina teve diferença significativa em $0,1 \%$. A disfunção do padrão respiratório alterou a morfologia dos arcos dentários ainda na fase de dentição decídua.

Moreira e Lino ${ }^{27}$ realizaram avaliação espirométrica e dimensional do arco dentário superior, das alterações provocadas pela expansão da maxila, em indivíduos respiradores bucais, na fase de dentição mista. Um aparelho expansor da maxila foi indicado na fase de dentição mista, aplicado para praticantes de esporte, do CEPEUSP (Centro de Práticas esportivas da Universidade de São Paulo), para respiradores bucais crônicos ou asmáticos. Após a expansão da maxila, os autores encontraram aumento de dimensões transversais da maxila tanto para a distância inter-molar quanto para a distância inter-caninos. A correlação do aumento da distância inter-caninos foi correlacionada estatisticamente, com a melhora do fluxo expiratório. Este fluxo apresentou melhoras significativas em direção ao padrão, com significado estatístico.

\section{DISCUSSÃO}

Do nosso ponto de vista, a Odontologia deve participar desde o início da carreira do atleta, nas bases, até a cuidadosa avaliação e acompanhamento do atleta profissional de alto rendimento esportivo dentro da Odontologia do Esporte para atletas de alto rendimento. O cirurgião dentista, portanto, é um profissional que deve sempre integrar a equipe de saúde que acompanha os esportistas de um clube, confederação ou associação esportiva. O nosso objetivo final é zelar pela saúde bucal e consequentemente, pela saúde integral do atleta, patrimônio do clube. Consideramos o ineditismo da proposta apresentada no âmbito do esporte nacional, como um modelo único e inovador, acrescentando nas confederações esportivas, a distinção de uma proposta, que pode servir em um futuro breve, como modelo para as modalidades esportivas e clubes.

Na cavidade bucal, potencialmente, reside um grande risco existente, número e variedade de bactérias e outros micro-organismos que frequentemente sofrem migrações para o ambiente intra-corporal. Essas bacteremias apresentam múltiplas etiologias: naturais, iatrogênicas e também àquelas decorrentes da própria atividade desportiva.

Muitas confederações, federações e clubes de ponta, das mais variadas modalidades desportivas, terceirizam o atendimento odontológico, somente na necessidade manifestada pelo atleta. Portanto não ocorre nenhum tipo de interação com o departamento médico, ou se ocorre provavelmente não de maneira satisfatória. Isso pode ser muito perigoso para a saúde do atleta, pois denota desconhecimento do potencial patogênico de muitas formas bacterianas, habitantes naturais da cavidade bucal, e suas possíveis manifestações em outros sistemas do organismo.

A inserção do cirurgião-dentista no universo do esporte de alto rendimento, não existe no nosso país e por isso, as publicações relativas ao tema, que apresentam qualidade e justificativas, na tentativa de sensibilizar os demais profissionais da saúde, dirigentes, treinadores e atletas, quanto a importância de uma boa saúde bucal, também são muito escassas. O objetivo final da incorporação do cirurgião-dentista dentro das equipes de saúde para o atleta, ainda não foi alcançado. É imprescindivel a ciência desta necessidade e suas exigências. Por bem, a classe odontológica inicia uma mobilização por uma nova legislação que garanta essas necessidades na saúde do esporte.

Convém ressaltar que, em muitas ocasiões, devido ao sobre treinamento, pré-treinamento ou atividade intensa de competição, o atleta estará atuando em condições excepcionais, com alterações significativas nos sistemas neuroendócrino, psicológico, imunológico e fisiológico.

$\mathrm{Na}$ atividade física de alto rendimento, no tecido muscular, a matriz extracelular estará impregnada de restos oriundos do metabolismo celular intenso, assim como submetida a processo inflamatório agudo local e por vezes sistêmico, em função da prática esportiva contínua, sugerindo um nicho satisfatório para instalação e proliferação de vários micro-organismos.

O aprendizado e a execução das técnicas de higienização para o controle do biofilme, ou da placa bacteriana oral, o estado do desgaste fisiológico e o histórico de lesões, segundo nossas concepções, são os principais parâmetros para que se estabeleça uma individualização do atendimento odontológico do atleta. Tanto no estabelecimento de uma periodicidade de intervenções, como também no uso ou não, de medicação antibiótica nas manobras mais invasivas, que o atleta necessite. Desse modo, no pior dos cenários, teríamos um atleta com alto índice de lesões intra-bucais, com componente orgânico de difícil recuperação, com péssima condição de saúde bucal e inadequada técnica de higiene oral. Em contrapartida, teríamos o atleta com baixíssimo índice de lesões, perfil de rápida recuperação muscular, ótima situação de saúde bucal com boa higienização. Todas as demais possibilidades estariam contidas no intervalo entre uma e outra possibilidade. O conhecimento do cirurgião dentista sobre a variedade destes perfis, estabelecerá o 
desenvolvimento de protocolos de atendimento para cada grupo de atletas ou para a necessidade individual do atleta, com o objetivo de promover sua saúde bucal e geral e seu máximo desempenho esportivo.

A função do cirurgião-dentista na equipe multidisciplinar de uma entidade esportiva é principalmente proporcionar aos atletas que em qualquer intervenção de promoção de saúde, preventiva ou terapêutica, que se possa minimizar o trânsito de microrganismos para outras áreas do organismo. Frente a todas estas linhas de pesquisa, evidenciando a odontologia do esporte, como uma necessidade nos padrões de vida da atualidade, a nossa proposta é de:

2.1. Valorizar e promover a saúde bucal e sistêmica do atleta, oferecendo ao patrimônio humano do clube uma abordagem inovadora em odontologia do esporte; com trabalho em equipe dos profissionais da área médica responsável.

2.2. Educação em saúde bucal. Quanto mais jovem for o indivíduo, no processo de educação e aprendizado do controle mecânico da placa bacteriana por escovação dentária e higiene da cavidade bucal corretas, menor o número de bactérias e micro-organismos presentes na microbiota bucal. Com esta ação educativa permanente, conseguiremos zerar as cáries dentais, a doença periodontal e minimizar significativamente o número de lesões musculares, articulares, de ligamentos e tendinites ao longo da vida esportiva do atleta. Nas categorias de base, o acompanhamento de um cirurgião-dentista, especialista em Odontopediatria, seria fundamental.

2.3. Manutenção da saúde bucal. Classificar a condição de saúde bucal do atleta profissional e da base, com o diagnóstico atual da situação médica e inserir o atleta em protocolos de atendimento pré-estabelecidos, baseados em exames clínicos, radiográficos e laboratoriais, fornecidos pelo departamento médico. Serão avaliadas as condições de índices de cárie, doença periodontal e classificação de mal-oclusão e sua gravidade; com a meta de se minimizar cada uma destas condições o quanto possível, desde sua inserção nas equipes.

2.4. Odontologia Ocupacional. Em muitos aspectos a odontologia do esporte e do exercício se equipara em preocupações de relação trabalhista. Portanto, é de total interesse da confederação ou clube, promover esta atuação e cuidado permanente com o que compõe individualmente ou em equipes; o seu patrimônio humano.

2.5. Odontologia para associados e escolares (triagem oral e odontológica). Os clubes em geral, possuem quadros associativos, o qual para a prática esportiva é submetido a exames médicos exigidos pelos Clubes. Nossa proposta prevê que também os exames odontológicos sejam exigidos e incorporados ao cotidiano da prática de esportes, em clubes, academias e escolas nas diferentes modalidades esportivas.

\section{CONSIDERAÇÕES FINAIS}

Recomendamos a atuação da odontologia na equipe de saúde de clubes, confederações, federações e associações esportivas em nosso país, pela evidente necessidade do contexto esportivo da atualidade.

Precisamos construir esta política de saúde bucal no esporte com a inclusão da odontologia e maior integração (multidisciplinalidade) entre as áreas de saúde do esporte de alto rendimento, como também, nos exercícios físicos como um todo.

Todos os autores declararam não haver qualquer potencial conflito de interesses referente a este artigo.

CONTRIBUIÇÕES DE AUTORES: Todos os autores contribuíram individual e significativamente para o desenvolvimento do manuscrito. GUP (0000-0002-8238-6167)* MG (0000-0002-6021-1331)* e RB (0000-0003-4848-8212)* foram os principais responsáveis pelo levantamento bibliográfico, seleção dos artigos e participação ativa da discussão dos trabalhos. MM (0000-0003-0838-8006)* foi a idealizadora do conceito "Odontologia para crianças e adolescentes, praticantes regulares de atividade física" e juntamente com ML (0000-0002-0107-2458) proporcionaram à discussão e a elaboração do texto um caráter acadêmico. *ORCID (Open Researcher and Contributor ID).

\section{REFERÊNCIAS}

1. Hernandez AJ. Perspectivas profissionais da Medicina do Esporte, Rev Med (São Paulo). 2012;91 (1):9-13.

2. Andreasen JO, Anderson L, Andreasen FM. Textbook of color atlas of traumatic injuries to the teeth. 3 rd ed. Copenhagen: Munksgaard; 1994.

3. Rosa AF, Rosa SB, Silva PRS, Roxo CDM, Teixeira AAA, Visconti AM, et al. Estudo descritivo de alterações verificadas em 400 jogadores de futebol. Rev Bras Med Esporte. 1999;5(2): 55-8.

4. Martinez AC, Alvarez-Mon M. O sistema imunológico (I): Conceitos gerais, adaptação ao exercício físico e implicações clínicas. Rev Bras Med Esporte. 1995;(3):120-5.

5. Boisseau N, Delamarche P. Metabolic and hormonal responses to exercise in children and adolescents. Sports Med. 2000;30(6):405-22

6. Feres M, Figueiredo LC. Da infecção focal à medicina periodontal. Rev Periodontia. 2007;17(2):14-20.

7. Melo da Silva JM, Marceliano MFV, Silva PAR, Lamarão SMS. Infecção endodôntico como fator de risco para manifestações sistêmicas. Rev Odont Unesp. 2007;36(4):357-64.

8. Matsumoto MSS. Avaliação in vitro das alterações do esmalte dentário de dentes permanentes submetidos à ação de bebidas energéticas [tese]. São Paulo: Faculdade de Odontologia, Universidade de São Paulo; 2008.

9. Cavalcanti AL, Xavier AFC, Souto RQ, Oliveira MC, Santos JA, Vieira FF. Avaliação in vitro do potencial erosivo de bebidas isotônicas. Rev Bras Med Esporte. 2010;16(6):455-8.

10. Silva FIC, Santos AML, Adriano LS, Lopes RS, Vitalino R, Sá NAR. A importância da hidratação hidroeletrolítica no esporte. Rev Bras Ci e Mov. 2011;19(3):120-8.

11. Segura R, Javierre C, Ventura JL, Lizarraga MA, Campos B, Garrido E. A new approach to the assessment of anaerobic metabolism: measurement of lactate in saliva. Br J Sports Med. 1996;30(4):305-9.

12. Cheuvront SN, Sawka MN. Avaliação da hidratação dos atletas, Sports Sci Exchange 97. 2005;18(2). Disponível em: http://www.gssiweb.org/pt-br/Article/ sse-97-avalia\%C3\%A7\%C3\%A3o-da-hidrata\%C3\%A7\%C3\%A3o-de-atletas

13. Kivlighan KT, Granger DA. Salivary al pha-amylase response to competition: relation to gender, previous experience, and attitudes. Psychoneuroendocrinology. 2006;31(6):703-14.

14. Silva RP, Natali AJ, Paula SO, Locatelli J, Marins JCB. Imunoglobulina salivar (Iga-s) e exercício: relevância do controle em atletas e implicações metodológicas. Rev Bras Med Esporte. 2009;15(6):459-66.
15. McArdle WD, Katch FI, Katch V. Fisiologia do exercício - nutrição, energia e desempenho humano. 7a. ed. Rio de Janeiro: Guanabara Koogan; 2011

16. Santos Oliveira L, Lins e Silva CE, Oliveira SF, Albuquerque FL, Costa MC. Volume salivar em resposta ao exercício físico progressivo. ConScientiae Saúde. 2011;10(2):363-8.

17. Needleman I, Ashley P, Petrie A, Fortune F, Turner W, Jones J, et al. Oral health and impact on performance of athletes participating in the London 2012 Olympic Games: a cross-sectional study. Br J Sports Med. 2013;47(16):1054-8.

18. Fernandes G. Estudo da associação entre bruxismo do sono, disfunção têmporo-mandibular e cefaléias primárias [dissertação]. Araraquara: Faculdade de Odontologia de Araraquara - Universidade Estadual Paulista "Júlio de Mesquita Filho; 2011.

19. Yamaga T, Yoshihara A, Ando Y, Yoshitake Y, Kimura Y, Shimada M, et al. Relationship between dental occlusion and physical fitness in an elderly population. J Gerontol A Biol Sci Med Sci. 2002;57(9):M616-20.

20. Osterberg T, Mellström D, Sundh V. Dental health and functional ageing. A study of 70-year-old people. Community Dent Oral Epidemiol. 1990;18(6):313-8.

21. Silva NM, Silva MA, Silva KNG. A influência do apertamento dentário funcional na força muscular durante a prática esportiva. Ter Man. 2011;9(45):558-63.

22. Costa SS. Odontologia esportiva na luta pelo reconhecimento. Rev Odontol UNICID. 2009;21 (2):162-8.

23. Silva AA, Bittencourt NFN, Mendonça LM, Tirado MG, Sampaio RF, Fonseca ST. Análise do perfil, funções e habilidades do fisioterapeuta com atuação na área esportiva nas modalidades de futebol e voleibol no Brasil. Rev Bras Fisioter. 2011;15(3):219-26.

24. Tuna EB, Ozel E. Factors affecting sports-related orofacial injuries and the importance of mouthguards. Sports Med. 2014;44(6):777-83

25. Assis C. Os rumos da odontologia do esporte no Brasil. Rev Bras Odontol. 2013;70(2):160-4.

26. Moreira M, de Paiva Lino A. Evaluation of palatal depth and width in mouth breathers with primary dentition. Int J Orofacial Myology. 1989;15(1):19-24.

27. Moreira M, Lino AP. Avaliação espirométrica e dimensional do arco dentário superior, das alterações provocadas pela expansão da maxila, em indivíduos respiradores bucais, na fase de dentição mista [tese]. São Paulo: Faculdade de Odontologia, Universidade de São Paulo; 1993. 